\title{
Considering the Effect of Reservoir Water Level Lifting on the Slope Stress Analysis of Seepage Field and Stress Field Coupling
}

\author{
Haize Pan", Rong Qin, Ting Mao, Mengjie Chen
}

School of Civil Engineering and Architecture, Southwest Petroleum University, Chengdu 610500, P.R. China

\begin{abstract}
This paper analyzes the slope stress analysis of seepage-stress field under the condition of water lifting of reservoir slope, taking a practical reservoir slope project for example, on the basis of investigation and study of the geological environment, the soil geology model of the reservoir slope is established. On the basis of interaction calculation module of the fluid structure in the software Geo-Studio and Biot theory, finite element method of seepage-stress field coupling is applied to study the variation of stress field of the reservoir slope mainly with strong weathering argillaceous sandstone and marl, on the condition that reservoir water level rise and fall. The maximum principal stress is mainly compressive stress, the tensile stress just distributes near the top of the slope; the minimum principal stress is mainly compressive stress.
\end{abstract}

Keywords: Fluid-solid coupling, reservoir slope, seepage-stress field, stress analysis, water level lifting.

\section{INTRODUCTION}

The slope stress analysis under reservoir water level lifting, there are well established in the literature and they are commonly used in practice. The numerical simulation of the displacement response history of a real-life system to a known seismic excitation has been performed using the finite element method and specially developed interface elements have been employed to model the discontinuities of the structure in the past by P. G. Asteris and his co-workers [1].

By constructing special grid system and intermediate boundary conditions, combined drain seepage system (horizontal drain pipe + transverse- longitudinal blind drainage ditch) is well achieved in the model and the results of model analysis are verified by the results of experiments. As the increase of the filling height, the seepage slope increases correspondingly by Rui-Li Lu and his co-workers [2].

The effects on the stability of the slope from mechanics between the water and rock interaction is mainly reflected on the dynamic change of the groundwater level making the slope stress environment deteriorative [3]. Typically, seepage field and stress field in the slope rock mass maintain a dynamic equilibrium in some way. When one of them changes, the other will automatically adjust to a new equilibrium through the link between them [4]. But, if one party changes over a certain range, the balance system is likely to be destroyed, then slope disasters will be induced $[5,6]$.

\section{THE FUNDAMENTAL OF SEEPAGE FIELD AND STRESS FIELD COUPLING ANALYSIS}

Water lifting process is seepage and stress and strain variation and interaction coupling process [7]. In this paper,

*Address correspondence to this author at the School of Civil Engineering and Architecture, Southwest Petroleum University, Chengdu 610500, P.R. China; E-mail: 120138424@qq.com on the basis of the fluid structure interaction calculation module in the software Geo-Studio and Biot theory $[8,9]$, finite element is adopted to build the equation, in which the node displacement and the pore water pressure are unknown at the same time [10-12]. Once the equations are solved, seepage field and stress field are obtained simultaneously [13-15].

In seepage field-stress field coupling analysis, the rock mass balance equations and flow equations are simultaneously calculated, mainly by using the virtual work principle [16-18]. The penetration is as the only force, namely:

$\int\left\{\varepsilon^{\cdot}\right\}^{T}\{\Delta \sigma\} d V=\int\left\{\sigma^{\cdot}\right\}\{F\} d V$

Where $\left\{\sigma^{\cdot}\right\}=$ Virtual displacement; $\left\{\varepsilon^{\cdot}\right\}=$ Virtual strain; $\{\sigma\}=$ Internal stress; $\{F\}=$ Penetration

and $\{\Delta \sigma\}=[D]\{\Delta \varepsilon\}+\{m\} \Delta u_{w}$

With the application of the numerical integral, the finite element numerical equation is obtained:

$$
\begin{gathered}
\Sigma[B]^{T}[D][B]\{\Delta \delta\}+\Sigma[B]^{T}[D]\left\{m_{H}\right\}(N)\left\{\Delta u_{w}\right\}=\Sigma F \\
\text { Where }[K]=[B]^{T}[D][B] ; \\
{\left[L_{d}\right]=[B]^{T}[D]\left\{m_{H}\right\}(N) ;\left\{m_{H}\right\}^{T}=\left\{\frac{1}{H}, \frac{1}{H}, \frac{1}{H}, 0\right\} ;}
\end{gathered}
$$

Where $[B]=$ Strain matrix; $[D]=$ Stress-strain matrix; $[K]=$ Stiffness matrix; $\left[L_{d}\right]=$ Joint matrix (coupling matrix); $[\Delta \delta]=$ Displacement vector increment; $\left[\Delta u_{w}\right]=$ Pore water pressure increment.

For saturated soil, coupling matrix $\left[L_{d}\right]$ can be written as: 


$$
\left[L_{d}\right]=[B]^{T}\left\{m_{H}\right\}(N),\{m\}^{T}=\langle 1,1,1,0\rangle
$$

In coupling analysis, seepage flow equation meets Darcy's law, namely:

$$
\frac{K_{x}}{\gamma_{w}} \frac{\partial^{2} u_{w}}{\partial x^{2}}+\frac{K_{\gamma}}{\gamma_{w}} \frac{\partial^{2} u_{w}}{\partial y^{2}}+\frac{\partial \theta_{w}}{\partial t}=0
$$

Where $K_{x}$-The permeability coefficient of X direction; $K_{y}$-The permeability coefficient of $\mathrm{Y}$ direction; $u_{w}$-The seepage velocity; $\theta_{w}$-The moisture content; $t$-The time.

By using the virtual work principle, the pore water pressure and volume strain also can be expressed in finite element, namely the virtual pore water pressure $\mathbf{u}_{w}^{*}$ is applied to flow equation. The following equation is obtained:

$\int u_{w}^{*}\left[\frac{k_{x}}{\gamma_{w}} \frac{\partial u_{w}^{*}}{\partial x^{2}}+\frac{k_{y}}{\gamma_{w}} \frac{\partial u_{w}^{*}}{\partial y^{2}}+\frac{\partial \theta_{w}}{\partial t}\right] d V=0$

Finishing equation,

$-\int\left[\frac{k_{x}}{\gamma_{w}} \frac{\partial u_{w}^{*}}{\partial x} \frac{\partial u_{w}}{\partial x}+\frac{k_{y}}{\gamma_{w}} \frac{\partial u_{w}^{*}}{\partial y} \frac{\partial u_{w}}{\partial y}\right] d V$

$+\int u_{w}^{*} \frac{\partial \theta_{w}}{\partial t} d V=\int u_{w}^{*} v_{n} d A$

Where $v_{n}$-The boundary flow And, volumetric water content $\theta_{w}=\frac{\beta}{3} \varepsilon_{v}-\omega u_{w}$ is substi-
tuted into the above equation to give,

$$
\begin{aligned}
& -\int\left[\frac{k_{x}}{\gamma_{w}} \frac{\partial u_{w}^{*}}{\partial x} \frac{\partial u_{w}}{\partial x}+\frac{k_{y}}{\gamma_{w}} \frac{\partial u_{w}^{*}}{\partial y} \frac{\partial u_{w}}{\partial y}\right] d V \\
& +\int u_{w}^{*} \frac{\partial\left(\beta \varepsilon_{v}-\omega u_{w}\right)}{\partial t} d V=\int u_{w}^{*} v_{n} d A
\end{aligned}
$$

By using the finite element approximation solution, formula 1 can be written as:

$$
\begin{aligned}
& -\int \frac{1}{\gamma_{w}}\left[B^{T}\right]\left[K_{w}\right][B]\left\{u_{w}\right\} d V-\int(N)^{T}(N)\left\{\frac{\partial\left(\omega u_{w}\right)}{\partial t}\right\} \\
& +\int(N)^{T}(m)^{T}[B]\left\{\frac{\partial(\beta \delta)}{\partial t}\right\} d V=\int\langle N\rangle^{T} v_{n} d V \\
& {\left[K_{f}\right]=\int[B]^{T}\left[K_{w}\right][B] d V,\left[M_{N}\right]=[N]^{T}[N],} \\
& {\left[M_{N}\right]=[N]^{T}[N]}
\end{aligned}
$$

Where $[B]=$ Hydraulic gradient matrix; $\left[K_{w}\right]=$ permeability coefficient matrix; $\left[K_{f}\right]=$ Element stiffness matrix; $[N]=$ Row vectors of deformation equation; $\left[M_{N}\right]=$ Area matrix; $\left[L_{f}\right]=$ Seepage coupling matrix; $\{m\}^{T}=$ Isotropic unit tensor, $\langle 1,1,1,0\rangle ; \delta=$ The node displacement;

When the time $t$ passes $\Delta t$, formulal can be integrated as follows,

$$
\begin{aligned}
& -\int_{t}^{t+\Delta t} \frac{1}{\gamma_{w}}\left[K_{f}\right]\left\{u_{w}\right\} d t-\int_{t}^{t+\Delta t}\left[M_{N}\right]\left\{\frac{\partial\left(\omega u_{t}\right)}{\partial t}\right\} d t \\
& +\int_{t}^{t+\Delta t}\left[L_{f}\right]\left\{\frac{\partial(\beta \delta)}{\partial t}\right\} d t=\int_{t}^{t+\Delta t}(N)^{T} v_{n} d A d t
\end{aligned}
$$

After numerical calculation, the final porosity flow equations are described as follows:

$$
\begin{aligned}
& \beta\left[L_{f}\right]\{\Delta \delta\}-\left(\frac{\Delta t}{\gamma_{w}}\left[K_{f}\right]+\omega\left[M_{N}\right]\right)\left\{\Delta u_{w}\right\} \\
& =\Delta t\left(\{Q\}_{\mid t+\Delta t}+\frac{1}{r_{w}}\left[K_{f}\right]\left\{u_{w}\right\}_{\mid t}\right)
\end{aligned}
$$

Where $\{Q\}=$ Boundary point flow;

$$
\beta=\frac{E}{H} \frac{1}{(1-2 v)}=\frac{2 K_{B}}{H} ; \omega=\frac{1}{R}-\frac{3 \beta}{H} ;
$$

Finally, the unit balance equation of finite element coupling analysis and the flow equation are obtained as follows:

$$
\begin{aligned}
& {[K]\{\Delta \delta\}+\left[L_{d}\right]\left\{u_{w}\right\}=\{\Delta F\}} \\
& \beta\left[L_{f}\right]\{\Delta \delta\}-\left(\frac{\Delta t}{\gamma_{w}}\left[K_{f}\right]+\omega\left[M_{N}\right]\right)\left\{\Delta u_{w}\right\} \\
& =\Delta t\left(\{Q\}_{\mid t+\Delta t}+\frac{1}{\gamma_{w}}\left[K_{f}\right]\left\{u_{w}\right\}_{\mid t}\right)
\end{aligned}
$$

\section{COUPLING ANALYSIS MODEL}

Project description: In this project, the landscape belongs to the terraced hillside area. The yellow sea elevation of the highest peak is $146.45 \mathrm{~m}$. Exploration area is located in transition zone of the slope foot and a plain. The yellow sea elevation of terrain height is $20-106.45 \mathrm{~m}$. From north to south, the terrain is lower and lower. As human activities transforming slope, more and more 1-10 $\mathrm{m}$ scarps and steep slopes are formed. The terrain slope in XiaoZifang area is less than 10 degrees, and the terrain is shaped as step with $21-41 \mathrm{~m}$ elevation. Aspect streets are mostly cement pavement. The terrain above Ring Road area was sloping with 20-25 degree slope, $100 \mathrm{~m}$ length and $41-90 \mathrm{~m}$ elevation. The northwest corner of exploration area is the platform edge area, made up of basal with the scarp distribution, and sill height is $10 \mathrm{~m}$; platform is on the top of scarp, relatively flat, with above $100 \mathrm{~m}$ elevation.

As a result of the limitation of experimental conditions failed to determine the required function of the volume of the water content on transient analysis, so using the closed solution of the fitting parameters define the curve, or using the measured size curve estimation method to get a estimate the volumetric water content function. This project uses the empirical formula Van Genuchten; the layers of soil mechanics parameter as shown in Table $\mathbf{1}$.

This paper uses mesh structure to establish a model, the graphics generates three finite element areas and two infinite element areas. The global element size is $1.5 \mathrm{~m}$. There are 
Table 1. Reservoir slope geological parameter values.

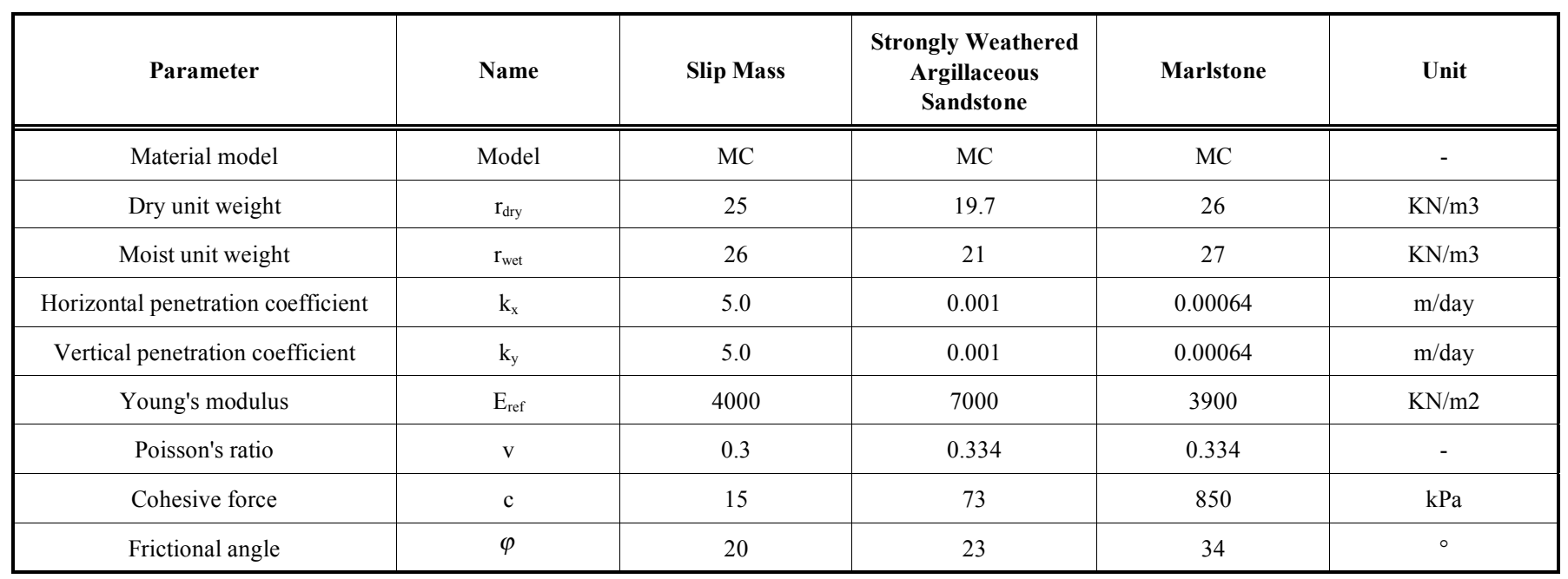

660 nodes, 562 elements in Mesh properties. Unstructured quadrilateral and triangular grid distribute in all finite element areas. On the rightmost, by using infinite regional grid, two infinite element areas is assumed to be on behalf of the infinite extension of reservoir slope. In the three former finite element areas, material property is defined as slippery body, strong weathering argillaceous sandstone and marl. While in the two latter areas, material property is strong weathering argillaceous sandstone and marl as shown in (Fig. 1).

Boundary conditions at the nodes can be defined as displacement and force etc. The finite element boundary can be defined as the pressure boundary. In this report, boundary conditions are that: $\mathrm{X}$ direction displacement of the left boundary is zero; $\mathrm{Y}$ direction is freedom; the right border is defined as infinite; two directions ( $\mathrm{X}$ and $\mathrm{Y}$ directions) displacements of bottom boundary are zero.

\section{STRESS-FIELD ANALYSIS}

\subsection{Water Level Rise Stage}

For the simulation of the reservoir water level rise, according to reservoir water level operation plan, the variation of the reservoir slope stress-field under the effect of water level lifting in the two phases of the water level rise and fall is studied, including the maximum principal stress, minimum principal stress, the maximum shear stress and so on. The results are shown in Fig. (2 7) below:

Fig. (2 and 3) show that: The maximum principal stress of reservoir slope is mainly compressive stress. With the water level rise, the maximum principal stress increases. The maximum principal stress is closer to the slope, the direction of the maximum principal stress is closer parallel to the slope;

Fig. (4 and 5) show that: The minimum principal stress of reservoir slope varies with the position of each point of slope body, as well as mechanical properties. The minimum principal stress is compressive stress near the slope. At the back of slope, the minimum principal stress is tensile stress, after impoundment, tensile stress gradually develops to internal.

Fig. (6 and 7) show that: The maximum shear stress of slope increases with the water level rise. On the top of the slope, the shear stress is maximum, and forms a stress

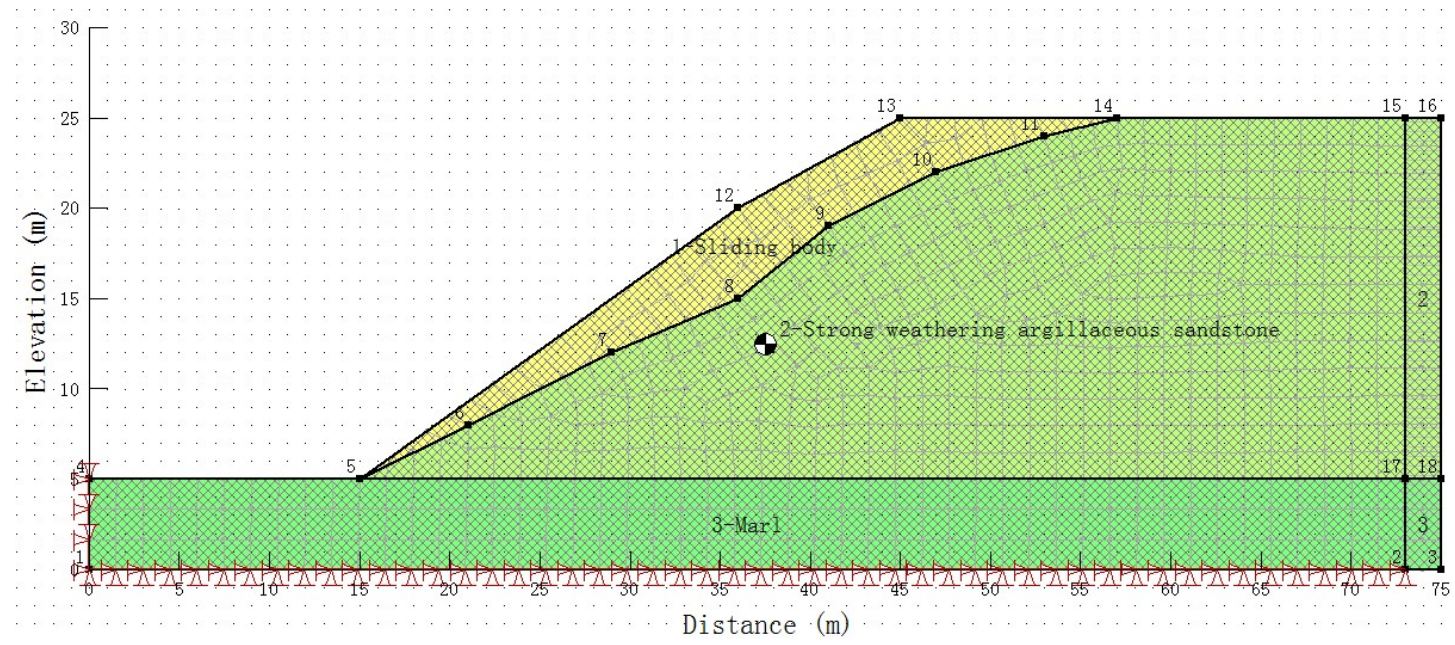

Fig. (1). Model diagram of slope fluid-solid coupling analysis with reservoir water level lifting. 


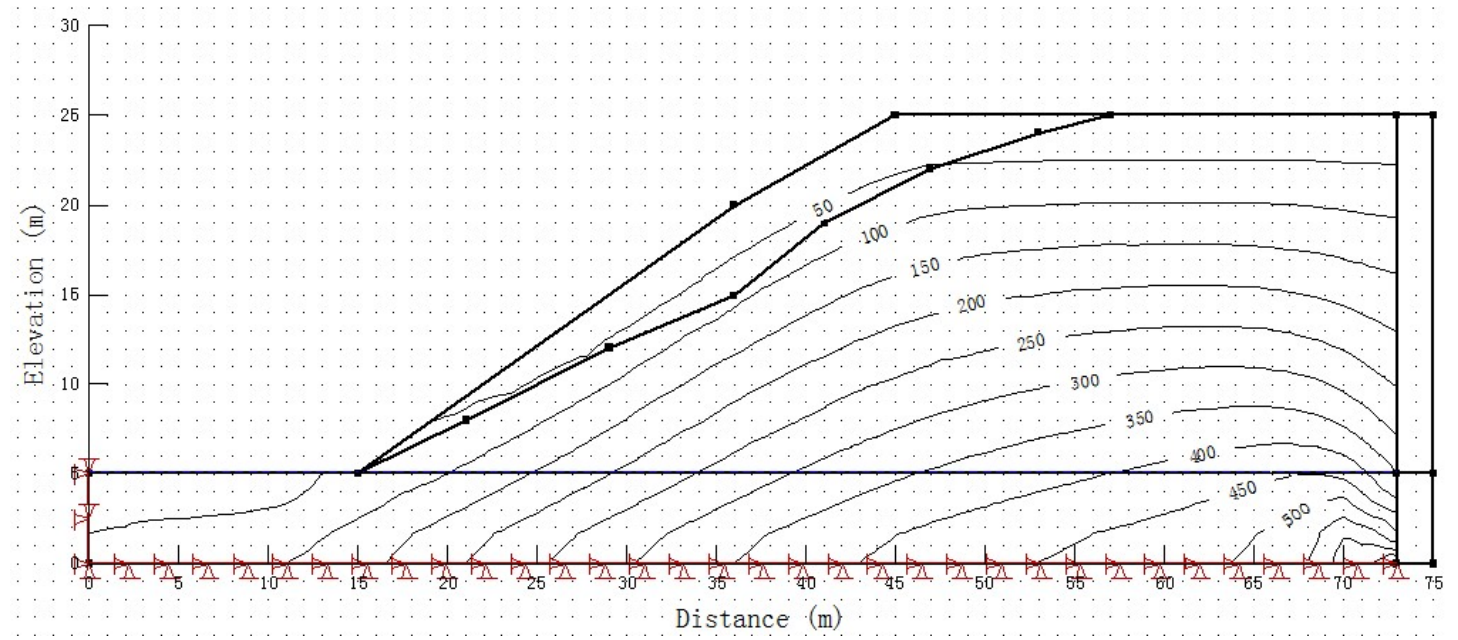

Fig. (2). The maximum principal stress distribution in the reservoir slope water level of $5 \mathrm{~m}$.

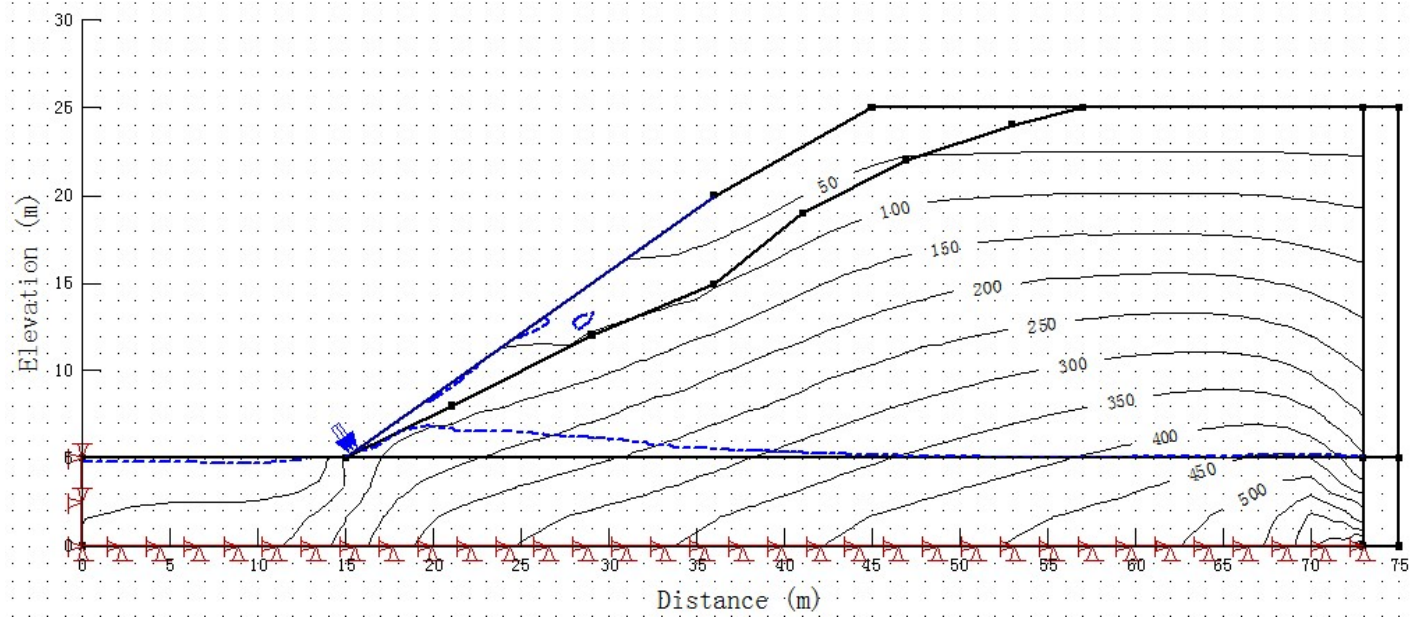

Fig. (3). The maximum principal stress distribution in the reservoir slope water level of $20 \mathrm{~m}$.

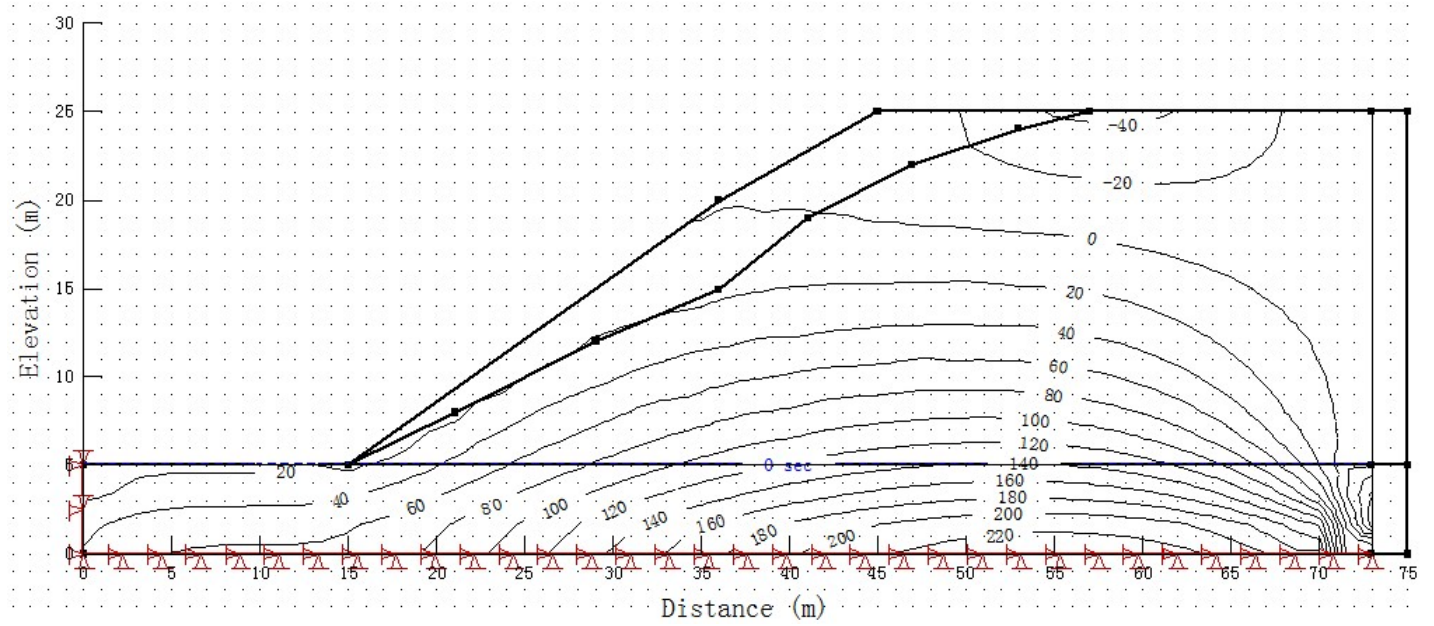

Fig. (4). The minimum principal stress distribution in the reservoir slope water level of $5 \mathrm{~m}$.

concentration zone. As a result, the part of the rock mass is easy to rip to form a crack surface nearly parallel with the slope.

\subsection{Water Level Fall Stage}

For the simulation of the reservoir water level fall, according to the same reservoir water level operation plan, the variation of the reservoir slope stress-field is studied, including the maximum principal stress, minimum principal stress, the maximum shear stress and so on. The results are shown in Fig. (8 13) below:

Figs. (8 and 9) show that: In the process of water level fall, the maximum principal stress of reservoir slope is 


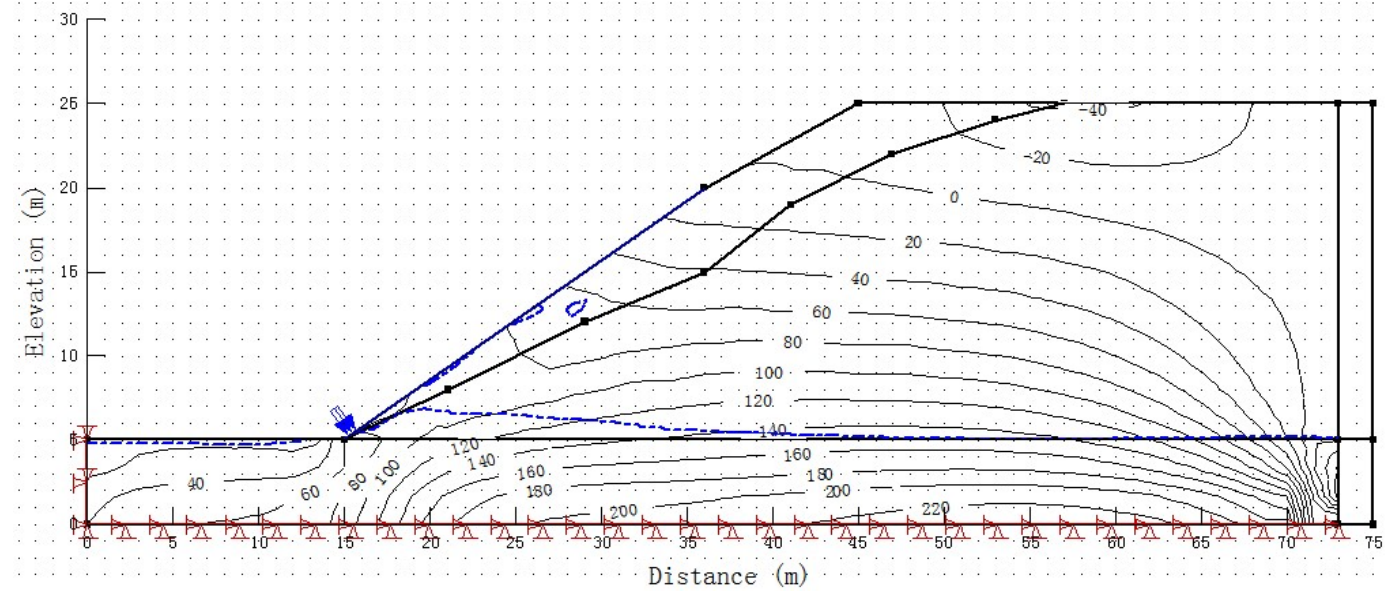

Fig. (5). The minimum principal stress distribution in the reservoir slope water level of $20 \mathrm{~m}$.

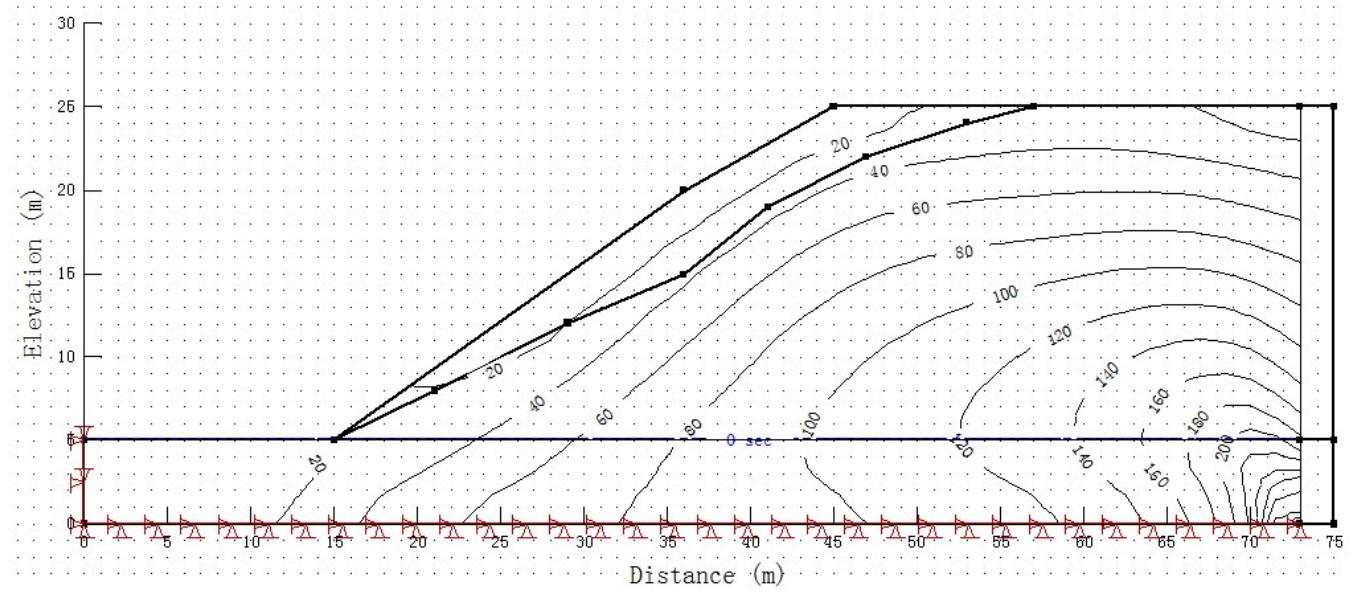

Fig. (6). The maximum shear stress distribution in the reservoir slope water level of $5 \mathrm{~m}$.

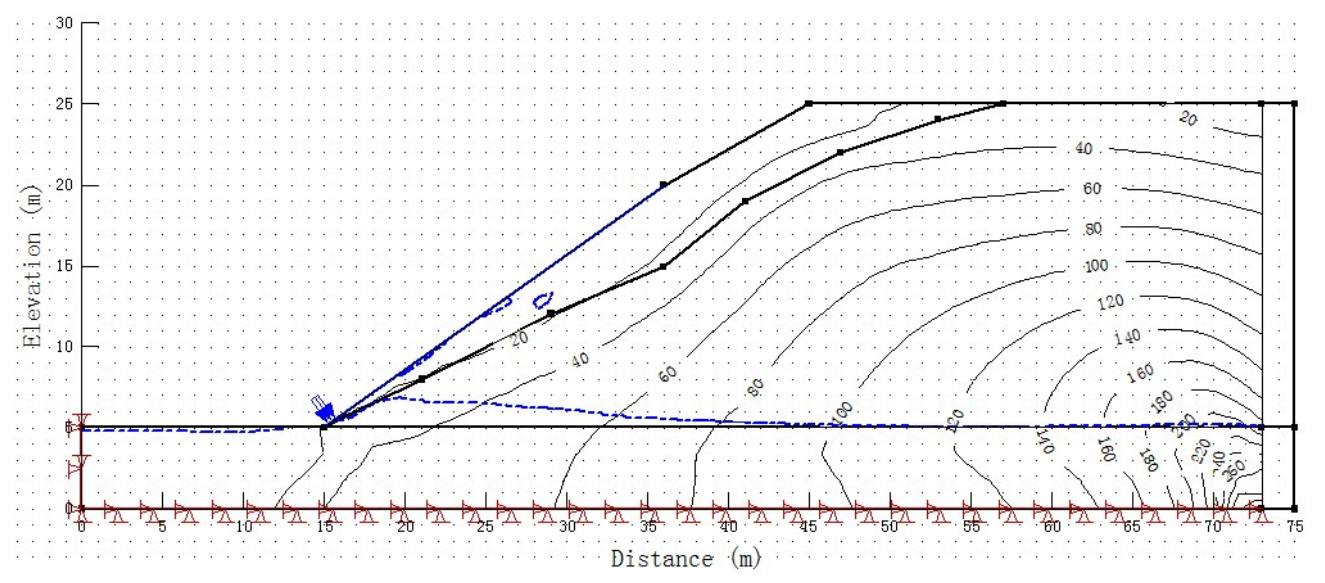

Fig. (7). The maximum shear stress distribution in the reservoir slope water level of $20 \mathrm{~m}$.

mainly compressive stress. The maximum principal stress is closer to the slope, the direction of the maximum principal stress is closer parallel to the slope. With water level fall, the maximum principle stress decreases, at the same time, the maximum principal stress on the top of the slope is mainly tensile stress.
Figs. (10 and 11) show that: The minimum principal stress of reservoir slope varies with the position of each point of slope body, as well as the mechanical properties. The minimum principal stress is compressive stress near the slope. Away from the slopes, the minimum principal stress is tensile stress at the back of slope, after impoundment, tensile stress gradually develops to internal. 


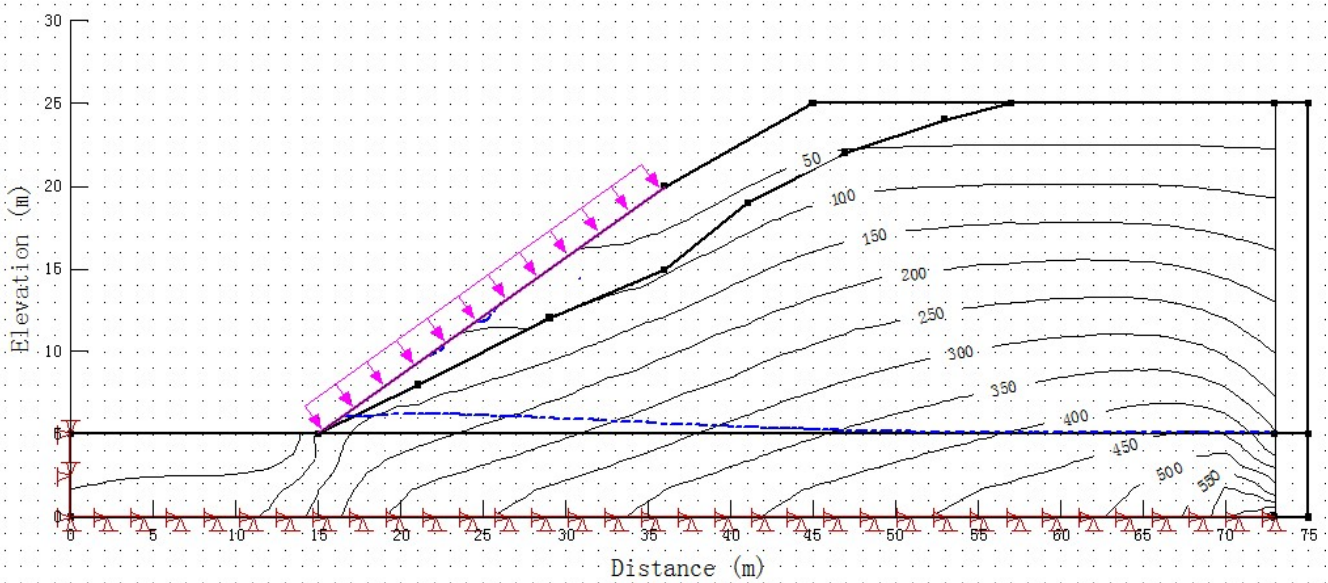

Fig. (8). The maximum principal stress distribution in the reservoir slope water level of $20 \mathrm{~m}$.

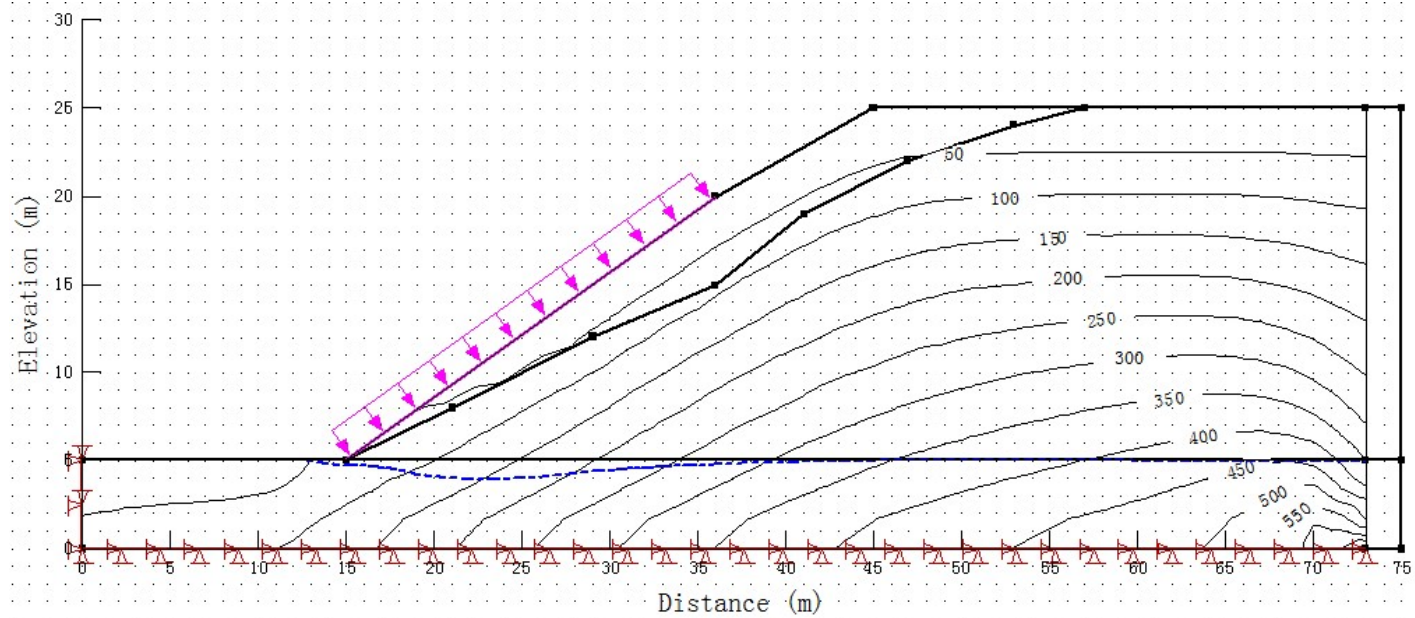

Fig. (9). The maximum principal stress distribution in the reservoir slope water level of $5 \mathrm{~m}$.

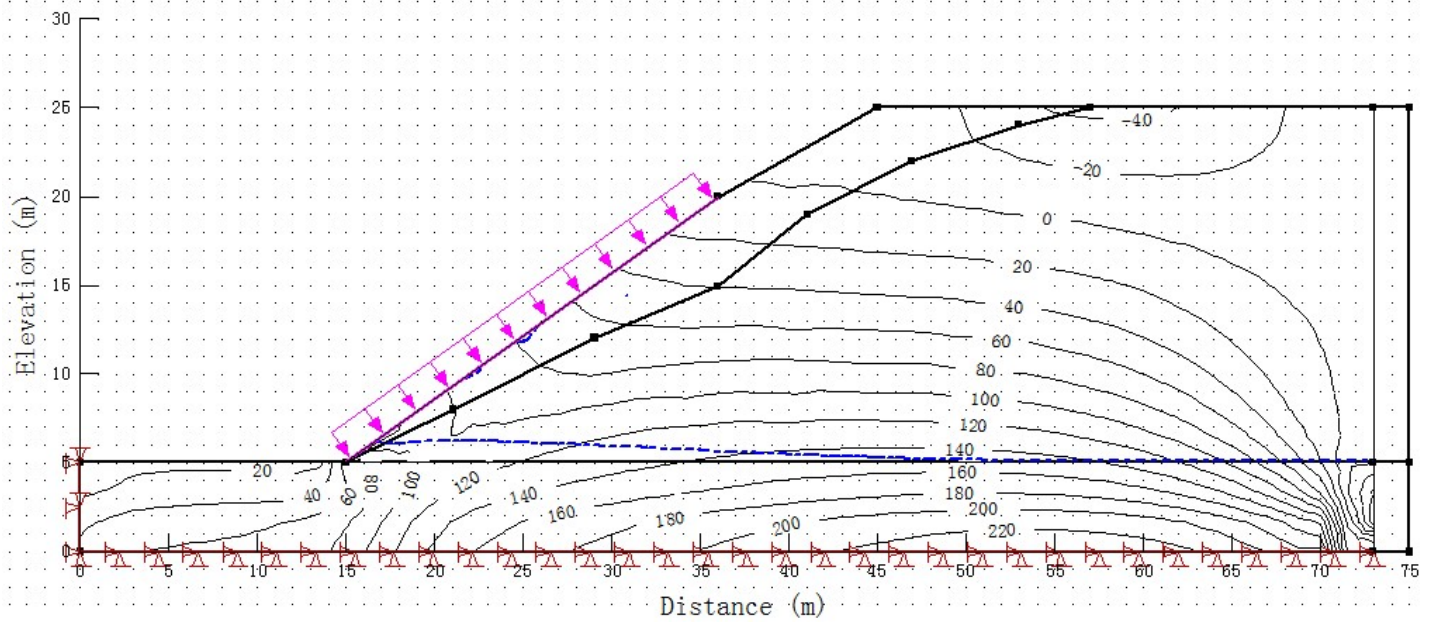

Fig. (10). The minimum principal stress distribution in the reservoir slope water level of $20 \mathrm{~m}$.

Figs. (12 and 13) show that: The maximum shear stress of slope decreases with the water level fall. On the top of the rear of slope, the shear stress is maximum, and forms a stress concentration zone. As a result, the part of the rock mass is easy to rip to form a crack surface nearly parallel with the slope.

\section{CONCLUSION}

This project analyzes the slope stress analysis of seepagestress field under the condition of water level lift, the water level varies $20 \mathrm{~m}$ to $5 \mathrm{~m}$. By simulating slope fluid-solid interaction under the effect of reservoir water level through 


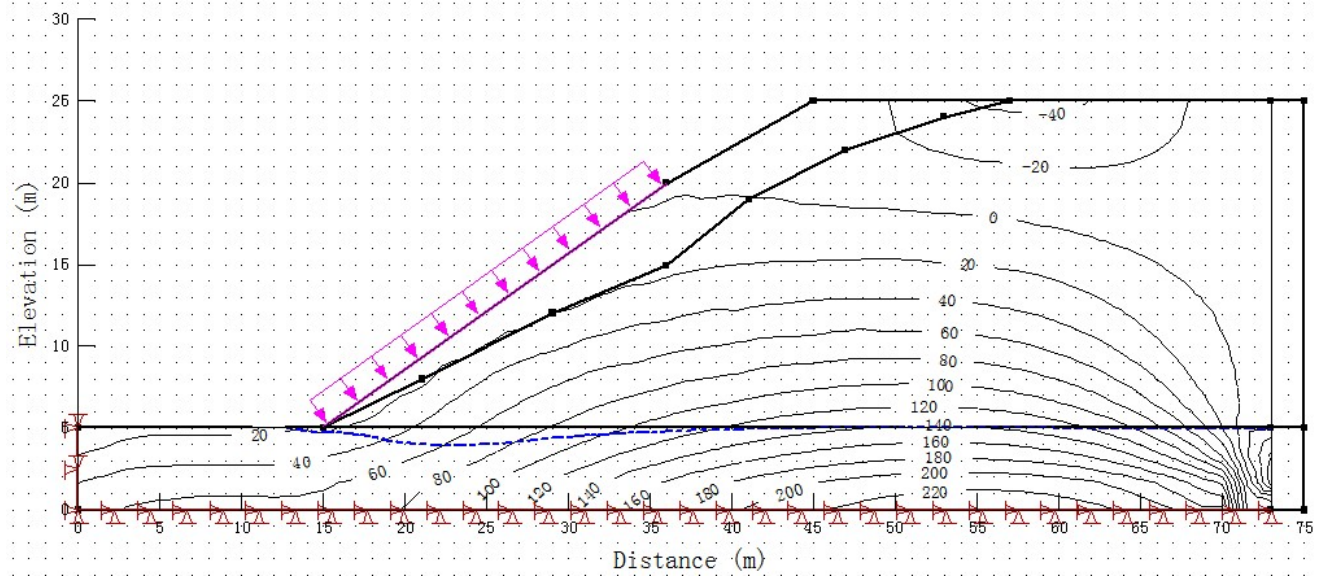

Fig. (11). The minimum principal stress distribution in the reservoir slope water level of $5 \mathrm{~m}$.

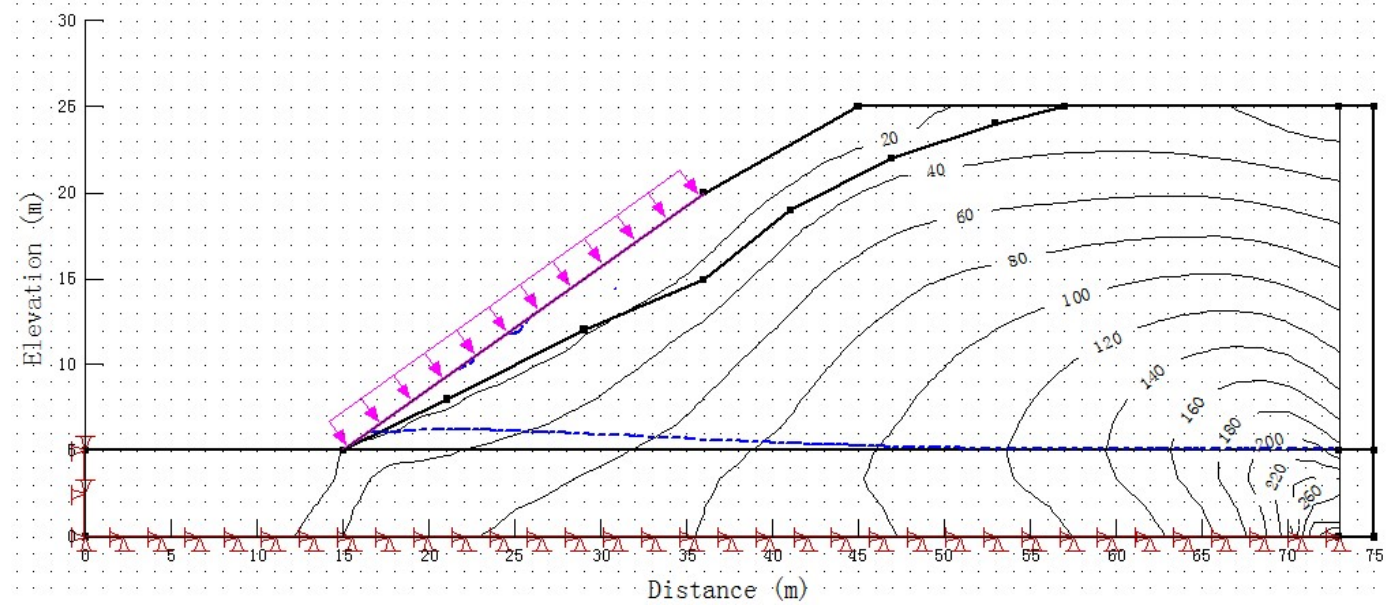

Fig. (12). The maximum shear stress distribution in the reservoir slope water level of $20 \mathrm{~m}$.

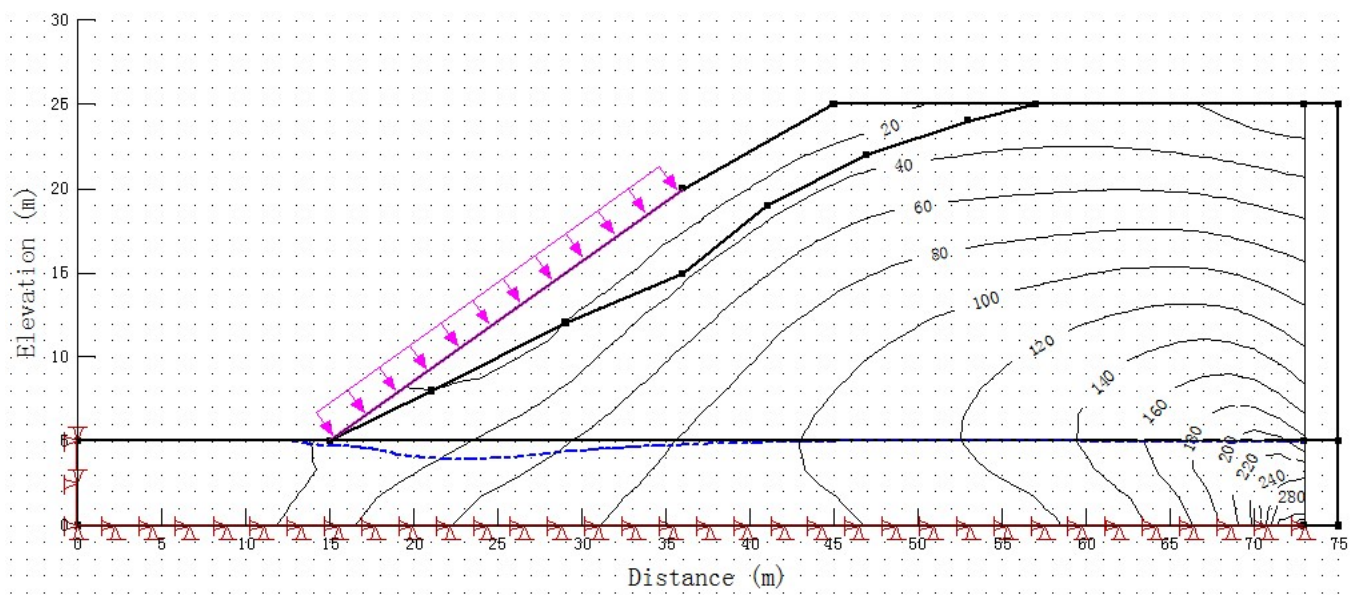

Fig. (13). The maximum shear stress distribution in the reservoir slope water level of $5 \mathrm{~m}$.

SEEP/W and SIGMA/W software, the conclusion can be obtained as follows:

(1) Through a comprehensive comparison of changes of the respective stress field of the reservoir slope in the process of water level rise, the maximum principal stress is mainly compressive stress, the tensile stress just distrib- utes near the top of the slope; with the water level rising, the maximum principal stress increases. The maximum principal stress is closer to the slope, the direction of the maximum principal stress is closer parallel to the slope.

(2) The minimum principal stress is compressive stress near the slope. At the back of slope, the minimum principal 
stress is the tensile stress, after the impoundment, the tensile stress gradually develops to the internal stress, the minimum principal stress of reservoir slope varies with the position of each point of slope body as well as mechanical properties.

(3) The maximum shear stress of slope increases with the water level rise and decreases with the water level fall. On the top of the slope, the shear stress is maximum, and forms a stress concentration zone. As a result, the part of the rock mass is easy to rip to form a crack surface nearly parallel with the slope.

(4) With the application of seepage-stress field coupling analysis theory, the stress-field variation of the reservoir slope mainly with strong weathering argillaceous sandstone and marl. The project is studied under the changes of water level. The results show that the change of water level has a great influence on the stress-field.

\section{CONFLICT OF INTEREST}

The authors confirm that this article content has no conflict of interest.

\section{ACKNOWLEDGEMENTS}

The authors would like to acknowledge the support of the Fundamental Research Funds for Sichuan province education department scientific research project and the State Administration of Work Safety Science and Technology Projects.

\section{REFERENCES}

[1] P. G. Asteris, and A. D. Tzamtzis, "Nonlinear Seismic Response Analysis of Realistic Gravity Dam-Reservoir Systems", International Journal of Nonlinear Sciences and Numerical Simulation, vol. 4 no. 4, pp. 329-338.

[2] R. L. Lu, D. P. Sun, and W. Wei. "Numerical simulation of seepage field in the tailing dam with draining seepage system", 2013 Fourth International Conference on, 2013, June 29-30.

[3] X. Li, "The research on three gorges reservoir area square stone landslide forecast criterion", Master's Thesis, Chengdu University of Technology, Chengdu, Sichuan, China, June 19, 2010.
[4] D. N. Petley, T. Higuchi and D. J. Petley, "Development of progressive landslide failure in cohesive materials", Geology, vol. 33, pp. 201-204, 2005

[5] G. Crosta, and F. Agliardi, "Failure forecast for large rock slides by surface displacement measurements", Canadian Geotechnical Journal, vol. 40, pp. 176-91, 2003.

[6] R. R. Cornelius, and P.A. Scott, "Materials failure relation of accelerating creep as empirical description of damage accumulation", Rock Mechanics and Rock Engineering, vol. 26, pp . 233-52, 1993.

[7] D. N. Petley, M. H. Bulmer, and W. Murphy, "Patterns of movement in rotational and translational landslides", Geology, vol. 30, pp. 719-22, 2002.

[8] D. N. Petley, S. A. Dunning, and N. J. Rosser, "The analysis of global landslide risk through the creation of a database of worldwide landslide fatalities", Landslide Risk Management, vol. 58, pp. 367-74, 2005.

[9] A. Federico, M. Popescu, and C. Fidelibus, "On the Prediction of the time of occurrence of a slope failure", International Symposium on Landslides, 2004, pp. 979-83.

[10] R. S. Jakka, G. V. Ramana, and M. Datta, "Seismic slope stability of embankments constructed with pond ash", Geotechnical and Geological Engineering, vol. 29, pp. 821-35, 2011.

[11] L. Xu, X. J. Qiao, C. X. Wu, and J. Iqbal, "Causes of landslide recurrence in a loess platform with respect to hydrological processes", Natural Hazards, vol.64, pp. 1657-70, 2012

[12] Z. Y. Wang, J. Xu, Y. P. Li, and Y. Wang, "Rheological damage FEA of hydro-mechanical coupling for rock mass", Journal of Central South University of Technology, vol. 14, pp. 324-28, 2007.

[13] X. S. Sun, J.I. Li, J. Liu, and R. Luo, "Coupling numerical analysis of seepage and stress fields after excavation of slope", Procedia Engineering, vol. 28, pp. 336-40, 2012.

[14] Z. R. Liu, H. B. Qiu, and M. Q. Peng, "Study of seepage and stability of foundation pit under continuous rainy conditions", Applied Mechanics and Materials, vol. 501-504, pp. 83-7, 2014.

[15] E. John, F. Alessio, and L. Lyesse, "Early warning thresholds for partially saturated slopes in volcanic ashes", Computers \& Geotechnics, vol. 49, pp.79-89, 2013.

[16] J. W. Godt, B. Ş. Kaya, N. Lu, and R. L. Baum, "Stability of infinite slopes under transient partially saturated seepage conditions", Water Resources Research, vol.48, pp. W05505-W05518, 2012.

[17] Y. L. Zhao, W. J. Wang, Y. H. Huang, P. Cao, and W. Wan, "Coupling analysis of seepage-damage - fracture in fractured rock mass and engineering application", Chinese Journal of Geotechnical Engineering, vol. 32, pp. 24-32, 2010.

[18] X. G. Song, S. F. Zhang, and Y. Y. Li, "In-situ dynamic monitoring and analysis of high slope stability", Rock and Soil Mechanics, vol. 26, pp. 1153-6, 2005.

(C) Pan et al.; Licensee Bentham Open.

This is an open access article licensed under the terms of the Creative Commons Attribution Non-Commercial License (http://creativecommons.org/licenses/by-nc/3.0/) which permits unrestricted, non-commercial use, distribution and reproduction in any medium, provided the work is properly cited. 